\title{
Assessment on Postharvest Handling Practices of Honey in Chena District, Southwestern Ethiopia
}

\author{
Dekamo Fiseha Lomiso \\ Southern Agricultural Research Institute, Bonga Agricultural Research Center, P.O.BOX: 101, Bonga, Ethiopia
}

\begin{abstract}
Honey is a natural food produced by honeybees from nectar or secretion of flowers. Even though honey production in Ethiopia is from a long period of time, the honey produced in the country in general in the study area in particular is still poor in quality due to handling problems. The objective of this study was to assess the postharvest handling practices of honey produced in Chena district, Southwestern Ethiopia. Majority (72.2\%) of the respondents use smoke and fire to harvest honey from traditional hives. Smoking materials used by respondents in the study area were animal dung $(42.9 \%)$, teff straw $(31.7 \%)$ and vernonia amegdalina leaves $(25.4 \%)$. According to the respondents, the smoking materials had negative effect on color, taste and moisture. Honey storage containers used by respondents in the study area were plastic containers (27\%), plastic sack (24.6\%), clay pot (19.8\%), tin (21.4\%) and animal skin $(7.2 \%)$. The result showed that honey harvesting, collecting, processing, straining and storing containers in the study area are traditional and not technically appropriate. Awareness should be created for beekeepers on the improved beekeeping system, type of containers they use and how to keep the quality of their honey.
\end{abstract}

Keywords: Postharvest; handling practice; honey; chena

DOI: $10.7176 / \mathrm{FSQM} / 89-04$

Publication date: August 31st 2019

\section{Introduction}

Beekeeping is one of an oldest economic activity in Ethiopia and its market surplus accounts for over $90 \%$ of the total harvest, $99.2 \%$ was consumed domestically and only $0.8 \%$ was exported due to low quality [1]. Quality issue is the main concern for export commodities, and the volumes of export in honey in Ethiopia have declined since the last decade. This is due to the deterioration in the quality of the honey during harvesting, postharvest handling and marketing [2].

The quality of Ethiopian honey is generally poor, as $95 \%$ of beekeepers follow traditional beekeeping practices with no improved techniques or technology [3]. Faulty handling from the time of its harvest until it reaches the market is responsible for its inferior quality. The type of hive used the method of harvesting and storing of honey play a vital role for determination of the quality of honey [4, 5].

Kaffa Zone has great potential for beekeeping activities due to the presence of diversified types of bee floras which used as pollen and nectar source for bees and suitable environmental conditions for bee colony and the production of honey [6]. However, due to the traditional method of beekeeping and postharvest handling practices used in the area the resource is underutilized. The honey obtained from a beekeeping sector of the area is still low as compared to the available potential of the country. Thus, the beekeepers in particular and the country in general are not benefiting from export market as expected. The need to assess the handling practices of honey produced in the Chena district is thus, necessary to provide basis for any intervention that will improve the honey industry.

\section{Materials and Methods}

\subsection{Description of the Study Area}

The study was conducted in Southern Nations, Nationalities and Peoples Regional State of Ethiopia, Kaffa zone, Chena district, at three kebeles (Figure 1). Chena is located from $510 \mathrm{~km}$ from Addis Ababa, capital city of Ethiopia and $738 \mathrm{~km}$ from Hawassa, the capital of the SNNPRS. The altitude of the district ranges from 1500 to 3000 m.a.s.1. The area has a varying topography composed of steep, mountains, and plateau. The area is located at $07^{\circ} 18^{\prime} 48^{\prime \prime} \mathrm{N}$ latitude and $036^{\circ} 16^{\prime} 25^{\prime \prime}$ ' longitude.

The district is bordered on the south by Benchi Maji zone, on the west by the Bita district, on the north by Gewata district, on the northeast by Ginbo district, and on the east by Decha district. The district has a total population of 158,449 , of whom 78,150 are men and 80,299 women; 11,629 or $7.34 \%$ of its population are urban dwellers (CDLFO, 2017). The total area of Chena district is estimated to be $901.92 \mathrm{~km}^{2}$ that is endowed with natural tropical rain forests with suitable climates that favor high honeybee population density, and forest beekeeping is widely practiced. According to CDLFO [7], the total households found in the district are 21,685, and of these households, 7752 are honey producers. Honey production is the main agricultural practice for households in the study area. 


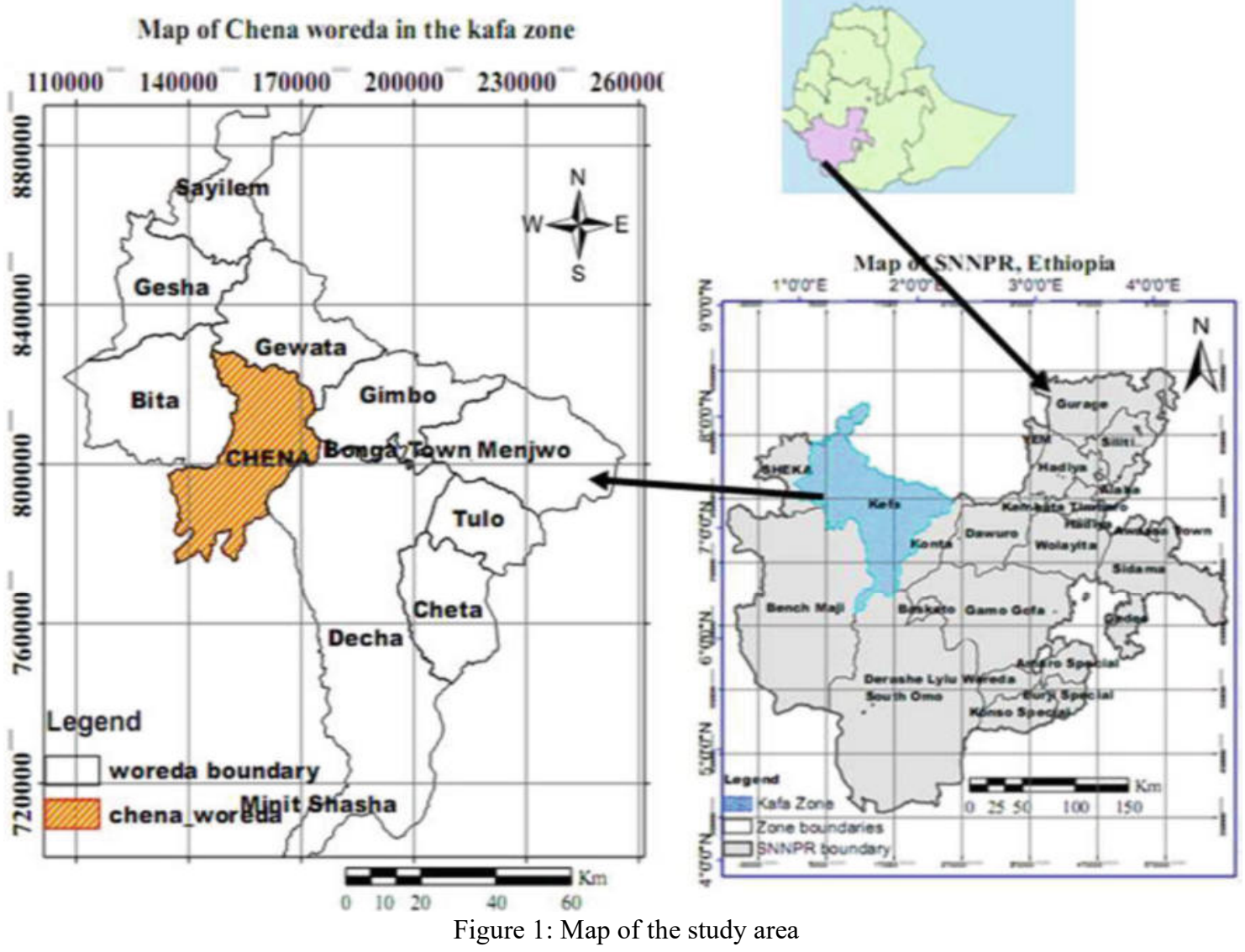

\subsection{Sampling Techniques and Sample Size Determination}

In this study, a multi-stage sampling technique was employed. Chena district was selected purposively from Kaffa zone based on its high honey production. The district actually comprises 42 kebeles of which 39 kebeles are rural. At the first stage, the kebeles were stratified into honey producers (27) and non producers (12), from these two groups honey producer kebeles were selected for the study.

In the second stage, from the stratified honey producer kebeles, three kebeles were selected randomly. At the third stage, total households that produce honey during 2017/18 from selected kebeles were identified and listed. Finally, using the population list of honey producers from the selected kebeles, a total of 126 honey producing households were randomly selected by employing probability proportional to size principle (PPS). The determination of sample size is resolved by means of Yemane [8], sampling formula with $95 \%$ confidence level and level of precision equal to $8 \%$ :

$$
\mathrm{n}=\frac{\mathrm{N}}{1+\mathrm{N}(e)^{2}}=\frac{650}{1+650(0.08)^{2}} \approx 126
$$

Where $n$ is sample size, $N$ is total households of selected kebeles and e is level of precision and $1=$ designates the probability of the event occurring.

\subsection{Data Sources and Methods of Data Collection}

In this study, both primary and secondary sources of data were used. Primary data was collected from beekeepers through structured questionnaire. A draft questionnaire was prepared and pre-tested in a preliminary survey conducted and based on the information generated through informal discussion with district rural development and agricultural offices and experts to test the relevance of the questionnaire before the main study. The enumerators who had knowhow on beekeeping were recruited to collect the data under the supervision of the researcher after training on the methods and the whole concepts of the data collections.

Secondary data, which were assumed to supplement the primary data, were obtained mainly from zone/district livestock and fishery development offices, previous research findings, journals, internets and other published and unpublished materials. 


\subsection{Statistical Analysis}

The data was analyzed using SPSS statistical software version 20 and Excel sheets. The survey data were analyzed and presented by tables using descriptive statistics like percentages, mean and frequency.

\section{Results and Discussion}

\subsection{Demographic characteristics of the respondents}

The demographic characteristics of the respondents in this study include sex, age, total family size and educational status. The information is based on the response obtained from 126 smallholder beekeepers.

Table 2: .Distribution of respondent's family size and age

\begin{tabular}{ccc}
\hline & Total sample sizes $(\mathbf{N}=\mathbf{1 2 6})$ & \\
\hline Variables & Range & Mean \pm SD \\
\hline Age (years) & $30-65$ & $45.35 \pm 7.80$ \\
Family size & $2-7$ & $4.80 \pm 1.33$ \\
\hline
\end{tabular}

$\mathrm{SD}=$ standard deviation

Majorities (77\%) of sample respondents interviewed were male (Table 2). The result of the survey indicated that beekeeping activities in Chena district is totally undertaken by males because the district is dominated by the traditional method of beekeeping practice. A very limited number of female participation in beekeeping activities in the present study is in agreement with the findings of Awraris et al. [6], Chala et al. [9] and Tewodros [10]. The limited number of female in beekeeping might be due to traditional beekeeping activity which is done by hanging traditional hives on the top of long trees in dense forests by climbing on the tree. This is because climbing on trees for hanging traditional hives is culturally considered as taboo for females. Harvesting is also done by climbing to the top of the tree, which is a very difficult task for females.

The survey result indicated regarding the age of the respondents that the average age of the sample respondents were 45.35 years (Table 1). This showed that beekeeping is an important economic activity that can be performed by all age groups, i.e. by younger and old people. The present result is in line with the findings of Tessega [11], Alemayehu [12] and Awraris et al. [6] who reported the predominance of active and productive heads of households.

The overall mean family sizes of the respondents were 4.80 (Table 1). The household size of a family might imply the level of dependency in the household or the labor force in the household. This labor force has involved in different beekeeping activities like beehive and apiary inspection, honey harvesting and colony management. Similarly, Workneh et al. [13] stated that beekeepers with large family size have interest and potential for promotion of improved technologies to improve productivity and incomes. Adopting improved box beehives demands additional labor and therefore, households with larger family size are more able to meet these demands.

Table 3: Sex and Educational status of respondents

\begin{tabular}{cccc}
\hline Variables & Category & Frequency & Percent \\
\hline Sex & Male & 97 & 77 \\
& Female & 29 & 23 \\
Education & Illiterate & 38 & 30.1 \\
& Basic education & 24 & 19 \\
& Primary education & 41 & 32.6 \\
& Secondary and above & 23 & 18.3 \\
& Total & 126 & 100 \\
\hline
\end{tabular}

The survey result showed that about $30.1 \%$ of households surveyed had no formal education at all, while majority (69.9\%) of them can read and write (Table 2). Out of the $69.9 \%$ about $32.6 \%$ and $18.3 \%$ of the respondent beekeepers have attended primary and secondary school, respectively. The rest $19 \%$ of the respondents had basic education. Their education had positive contribution to the success of beekeeping activities in the study area. Formal education is important to farmers to adopt modern inputs and technologies in beekeeping sector. Thus, farmers (beekeepers) need to get basic education for the reasons of adopting new technologies. Education is an important factor which if lacking can negatively impact on future improved beekeeping and livestock production. The present result of the study indicated that most respondents of the study area can easily adopt the extension services and bee related technologies provided. This higher literacy level may also enable respondents to access relevant information that will stimulate honey production. The present literacy level $(69.9 \%)$ is in line with the report of Tewodros [10] who have reported that more than $62.5 \%$ of the sampled respondents of Amhara region were literate. 


\subsection{Postharvest Handling Practices Honey in the Study Area}

Table 4: Methods of smoking during harvesting

\begin{tabular}{ccc}
\hline Methods of smoking & Frequency & Percent \\
\hline Smoke & 32 & 27.8 \\
Smoke and fire & 94 & 72.2 \\
Total & 126 & 100 \\
\hline
\end{tabular}

The majority (72.2\%) of respondents used smoke and fire in traditional log hives. The reason for their preference was due to the fact that these hives are placed on very tall trees making their harvesting difficult (Table 3 ). According to the respondents it was placed on very tall trees to protect the hives from predators which eat the honey. The farmers with traditional log hives reported that harvesting from the traditional hives is done at night. This affects honey quality because smoke and ashes from the fire ends up mixing with the harvested honey. The present result is in line with the findings of Alemayehu [12] and Awraris e et al. [6] who reported the smoke and fire employed while harvesting honey may dust the honey with ash and the honey may absorb the smoke which cause contamination to the honey.

Table 5: Smoking materials in the study area

\begin{tabular}{cccc}
\hline Description & Response & n & \% \\
\hline Honey smoking materia & Animal dung & 54 & 42.9 \\
& Vernonia amegdalina leaves & 32 & 25.4 \\
& Teff straw & 40 & 31.7 \\
& Total & 126 & 100 \\
\hline Is there negative effect & Yes & 85 & 67.5 \\
of smoking on honey & & & \\
quality? & No & 41 & 32.5 \\
& Total & 126 & 100 \\
\hline If yes, what are effects c & Changes color, taste and moisture & 45 & 53 \\
honey quality? & & & \\
& Color & 17 & 20 \\
& Taste & 13 & 15.3 \\
\end{tabular}

$\mathrm{n}=$ number of sampled respondent; $\%=$ percent

Smoking materials are important agent in manipulating beekeeping whenever inspecting hive and harvesting honey to remove honeybees. The smoking material is varied from place to place. To get rid of the bees from the comb and avoid stinging of honeybees, beekeepers of the study areas used smoke of different materials such as teff straw (31.7\%), animal dung (42.9\%) and Vernonia amegdalina (25.4\%) (Table 4). They smoke the hive from which they are going to harvest honey for long times and this results in changing the color and taste of the honey, which are the very important parameters for honey quality. Contrary to this, Kebede and Lemma [14] who indicated that $67.4 \%$ of interviewed beekeepers in Adami Tulu Jido Kombolcha district of Ethiopia use wood for smoking during harvesting while the rest of beekeepers use dung, old clothes and combinations of wood, animal dung and old clothes. This indicates that the smoking materials variation from place to place. Besides this, beekeepers were asked either these smoking materials have effect on honey quality or not and majority $(67.5 \%)$ of the respondents replied that smoking had negative effect on honey quality if not used appropriately, but $32.5 \%$ of the respondents replied as it had no negative effects on quality of honey if used appropriately. Those replied as smoking materials had negative effects on honey quality mentioned that as it change / affect color, taste and moisture together $(53 \%)$, color $(20 \%)$, taste $(15.3 \%)$ and moisture $(11.7 \%)$ of honey (Table 4$)$. Similarly, Tessega [11] and Jony [15] revealed that excessive use of smoking during honey harvesting is one of the critical problems that affect the quality of honey. This might be due to traditional way of using this smoking material and inappropriate methods of smoking. In addition, Beyene and Marco [4] also reported excessive smoking using locally available smoking materials during honey harvesting is the main problems in honey quality.

Table 6: Honey collecting materials in the study area

\begin{tabular}{ccc}
\hline Honey collecting materials & Frequency & Percent (\%) \\
\hline Plastic sack & 37 & 29.4 \\
Animal skin sack & 11 & 8.7 \\
Plastic containers & 55 & 43.7 \\
Clay pot & 23 & 18.2 \\
Total & 126 & 100 \\
\hline
\end{tabular}


Due to tradition, culture and availability of materials, containers of honey in Ethiopia vary from place to place [11]. Beekeepers in the study area used clay pots, plastic containers, the sack prepared from the skin of animals, tin, and a plastic sack prepared for honey collection and storage. $43.7 \%$ of the respondents in the study area collect their honey in plastic containers when they harvest it. The second honey collecting material reported by respondents in the study area are plastic sack (29.4\%) and the rest of the respondents collect honey in the clay pots and animal skin sack (Table 5).

Table 7: Honey storage materials

\begin{tabular}{ccc}
\hline Storage materials & Frequency & Percent \\
\hline Plastic sack & 31 & 24.6 \\
Plastic containers & 34 & 27 \\
Tin/barrel & 27 & 21.4 \\
Clay pot & 25 & 19.8 \\
Animal skin & 9 & 7.2 \\
Total & 126 & 100 \\
\hline
\end{tabular}

According to the data analyzed, plastic containers (27\%), plastic sack (24.6\%), clay pot (19.8\%), tin/barrel $(21.4 \%)$ and animal skin (7.2\%) were used to store honey (Table 6). However, except the plastic materials, most of storage containers aforementioned were technically not appropriate storage containers and some of respondents were using unclean collecting or storing materials, like the plastic sack of urea or Dap fertilizer which has a chemical content that can spoil the honey quality and result in serious quality deterioration. The only measure they took to use the sack was that they simply washed the sack with water before they used it. Similarly, Nuru [15], Alemayehu [12] and Awraris et al. [6] indicated that as honey was also collected and stored in traditional containers such as clay pot, animal skin/hide, plastic sack and tin. They also reported that honey quality is reduced when stored in traditional containers. Such traditional containers will absorb moistures or may change the flavor of honey and deteriorate the quality of honey during storage. In addition, according to the findings of Beyene and Marco [4], poor post-harvest handling and inappropriate storage containers often results in poor honey quality.

Table 8: Straining materials in the study area

\begin{tabular}{cccc}
\hline Description & Response & N & \% \\
\hline Honey straining & Yes & 36 & 28.6 \\
& No & 90 & 71.4 \\
& Total & 126 & 100 \\
\hline Materials used for straining & Sieve & 18 & 50 \\
& Using hand & 9 & 25 \\
& Cloth & 9 & 25 \\
& Total & 36 & 100 \\
\hline
\end{tabular}

$\mathrm{n}=$ number of sampled respondent; $\%=$ percent

For straining process respondents used straining materials to prevent dead bees and other particles from passing through sieve to strain their honey to obtain pure honey for sale. Majority $(71.4 \%)$ of the farmers do not strain honey. According to the survey result, only $28.6 \%$ of the sampled households strains their honey before sale using sieve $(50 \%)$ or clothes $(25 \%)$, with the help of solar energy and/or sometime by hand by simple drainage to remove the beeswax and any floating impurities simply using their hand (25\%) (Table 7). The respondents stated that straining influences the consistency, level of particles and dust as well as contamination of honey with microorganisms and needs to be done with precaution and under hygienic conditions.

Table 9: Reasons for not straining honey

\begin{tabular}{ccc}
\hline Reasons for not straining honey & Frequency & Percent \\
\hline Lack of straining materials & 8 & 8.9 \\
Lack of knowledge of how to strain & 40 & 44.4 \\
Lack of knowledge and straining materials & 42 & 46.7 \\
Total & 90 & 100
\end{tabular}

The farmers who do not strain honey reported their reason that they lacked knowledge of straining (44.4\%), lack of straining materials $(8.9 \%)$ and lack of both knowledge and materials $(46.7 \%)$ (Table 8). Similarly, Subramanian et al. [16] stated that straining is achieved using cloth or nylon bags, which are often cleaned to take away the suspended particles materials.

\section{Conclusion}

Majority of beekeepers in the study area practice traditional beekeeping system by hanging beehives on long trees in the forest with no management care for bees and bee products. The result showed that the night time harvesting of honey has affected honey quality. The result also showed that honey harvesting, collecting, processing, straining 
and storing containers are traditional and not technically appropriate. Therefore, action to be taken by responsible stakeholders and awareness should be created for the beekeepers on improved beekeeping system and technologies as well as postharvest handling techniques of honey. Moreover, provision of standard honey collecting and storage containers with affordable price to the beekeepers in the area can minimize inappropriate container that exposes the honey for quality deterioration.

\section{Conflict of interest}

The authors would like to declare that this study was carried out, mainly for academic research purpose without any conflict of interest.

\section{Acknowledgements}

We would like to thank Southern Agricultural Research Institute Ethiopia for their logistic support; Hawassa University, School of Human Nutrition, Food Science and Technology for laboratory service and Mr.Endale Ashenaf for his assistance in the laboratory work.

\section{References}

1. Hartmann, I.2004. "No Tree, No Bee - No Honey, No Money": The Management of Resources and Marginalization in Beekeeping Societies of South West Ethiopia. Paper submitted to the Conference: Bridging Scales and Epistemologies, Alexandria, March 17 - 20.

2. Beyene Tadesse and David Phillips. 2007. Ensuring Small Scale Producers in Ethiopia to Achieve Sustainable and Fair Access to Honey Markets. pp.64.

3. Oxfam Rudenko I. 2008. Value Chains for Rural and Regional Development: the case of cotton, wheat, fruits and vegetables value chains in the Lower Reaches of the Amu Darya River, Uzbekistan, pp. 18-27.

4. Beyene Tadesse and V. Marco. 2014. Assessment of constraints and opportunities of honey production in Wonchi District South West Shewa Zone of Oromia, Ethiopia. American Journal of Research Communication 2(10), 342-353.

5. Kebede Tesfaye and LemmaTesfaye. 2007. Study of honey production system in Adami Tulu Jido Kombolcha District in Mid Rift Valley of Ethiopia. Livestock Research for Rural Development 19(11).

6. Awraris Getachew Shenkute, Yemisrach Getachew, Assefa Dejen, NuruAdgaba, Ganga Gebeyehu and Bonga, W.A. 2012. Honey production systems (Apismellifera L.) in Kafa, Sheka and Bench-Maji zones of Ethiopia. Journal of Agricultural Extension and Rural Development Vol. 4(19), pp. 528-541.

7. CDLFO (Chena District Livestock and Fishery Office). 2017. Livestock extension profile of the district.

8. Yamane, T. 1967. Statistics: An Introductory Analysis, 2nd Edition, New York: Harper and Row.

9. Chala Kinat, Taye Toleramariam and Kebede Debele. 2011. Quality evaluation of honey produced in Gomma Woreda of South Western Ethiopia, Jimma University, College of Agriculture and Veterinary Medicine. Livestock research for rural development 23(9), 341 - 349.

10. Tewodros Alemu. 2010. Assessment of Honeybee Production Practices and Honey Quality in Sekota Woreda of Waghimra Zone, Ethiopia. MSc Thesis Presented to the School of Graduate Studies of Haramaya University. Pp.122.

11. Tessega Belie. 2009. Honeybee Production and Marketing Systems, Constraints and Opportunities in Burie District of Amahara Region, Ethiopia. M.Sc. Thesis.

12. Alemayehu Kebede. 2011. Honey Bee Production Practices and Honey Quality in Silti Wereda, Ethiopia. M.Sc. thesis presented to Haramaya University, Eastern Ethiopia. Research Gates pp.560 - 686.

13. Workneh Abebe. 2011. Identification and documentation of indigenous knowledge of beekeeping practices in selected districts of Ethiopia. Journal of Agricultural Extension and Rural Development, 3(5), 82-87.

14. Jony Girma Meshesha. 2011. Impact of Contract Farming on Household Income of Smallholder Farmers: The Case of Organic Honey Production in South West Ethiopia, Sheka Zone. Wageningen Unversity. Available at: < http://edepot.wur.nl/193737 > [accessed on 09/07/2017].

15. Nuru Adgaba.1999. Quality state and grading of Ethiopian honey. pp. 74-82. Proceedings of the first National Conference of Ethiopian Beekeepers Association (EBA), June 7-8, Addis Ababa, Ethiopia.

16. Subramanian, R., Hebbar, H. U. and Rastogi, N. K. 2007. Processing of honey: A review. International Journal of Food Properties 10, 127 - 143. 